\title{
Hybrid Cell-Penetrating Foldamer with Superior Intracellular Delivery Properties and Serum Stability
}

\author{
Céline Douat, ${ }^{\dagger}{ }^{\dagger}$ Mégane Bornerie, ${ }^{\dagger}$ Stéphanie Antunes, ${ }^{\dagger}$ Gilles Guichard ${ }^{+*}$ and Antoine Kichlers ${ }^{*}$ \\ ${ }^{\dagger}$ Univ. Bordeaux, CNRS, CBMN, UMR 5248, Institut Européen de Chimie et Biologie, 2 rue Robert Escarpit, F-33607 \\ Pessac, France. \\ ${ }^{\ddagger}$ Department Pharmazie, Ludwig-Maximilians-Universität, Butenandtstraße 5-13, D-81377 München, Germany \\ ${ }^{\S}$ Equipe 3Bio, CAMB 7199 CNRS—Univ. Strasbourg, Faculté de Pharmacie, 74 route du Rhin, F-67401 Illkirch cedex, \\ France.
}

\begin{abstract}
Sequence specific molecules with high folding ability (i.e. foldamers) can be used to precisely control the distribution and projection of side chains in space and have recently been introduced as tailored systems for delivering nucleic acids into cells. Designed oligourea sequences with an amphipathic distribution of Arg- and His-type residues were shown to form tight complexes with plasmid DNA, and to effectively promote the release of DNA from the endosomes. Herein, we report the synthesis of new cell-penetrating foldamer sequences in which the foldamer segment is conjugated via a reducible disulfide bond to a ligand that binds cell-surface expressed nucleoproteins with the idea that this system could facilitate both assemblies with nucleic acids and cell entry. This new system was evaluated for delivery of DNA in several cell lines and was found to compare favorably with all comparators tested (DOTAP and b-PEI as well as a number of known cell penetrating peptides) in various cell lines and particularly in culture medium containing up to $50 \%$ of serum. These results suggest that this dual molecular platform which is long lasting and non-cytotoxic could be of practical use for in vivo applications.
\end{abstract}

\section{INTRODUCTION}

In recent years, in a context of research seeking for modern pharmaceutical strategies, there has been a strong interest in the development of new and safe transport systems for the intracellular delivery of drugs and biomolecules such as nucleic acids (NA). A large fraction of engineered molecular transporters are inspired by cell-penetrating peptides $(\mathrm{CPPs})^{1,2,3}$ and share a common chemical feature i.e. the presence of multiple guanidinium units in their structure (either part of the main chain or as side chain appendages). ${ }^{4}$ Guanidinium moieties facilitate cell intake by providing key interactions with anionic phosphate head groups of membrane lipids ${ }^{5,6,7}$ and also mediate NA condensation and transfection. ${ }^{89}$ Seminal works by Wender et al. have shown the possibility to efficiently mimic arginine-rich CPP with guanidinium-containing oligocarbamates,${ }^{10}$ a class of backbone that has been reinvestigated recently by Kumar et al. for NA delivery. ${ }^{11}$ Meanwhile, with the advent of foldamers, ${ }^{12,13}$ various folded molecular architectures have been investigated for their capacity to spontaneously cross cellmembranes. Peptoids, ${ }^{14,15,16} \beta$ - and $\gamma$-peptides ${ }^{17,18,19,20,21,22}$ and aromatic oligoamides ${ }^{23,24}$ have shown promising results in term of cellular uptake. It has been postulated that the folded topology of these synthetic oligomers could play a key role in cell-membrane crossing. In most cases the defined helical geometry segregates the guanidinium moieties on one face of the structure thus conferring a facial amphiphilicity to these folded systems. ${ }^{25}$ This concept was also applied successfully to $\alpha$-peptides, recent examples includ- ing the development of rigidified cationic polyproline II helix architectures, ${ }^{26,27}$ and stabilized $\alpha$-helices containing either aliphatic or cationic $\alpha, \alpha$-disubstituted amino acids $^{28,29,30}$ or hydrocarbon crosslinks between side chains. ${ }^{31}$ Despite these significant advances, the interplay between folding, guanidinium distribution and cell penetration is often investigated in the absence of cargo and only few studies have reported cellular delivery of active molecules such as NAs. ${ }^{25}$

In this context, we have recently designed a first generation of cationic urea-based cell-penetrating foldamers (CPFs) as gene delivery system and we have shown that by introducing thiol moieties for effective foldamer dimerization (e.g. 1), we could 1) amplify the coating of 2.5-helical oligoureas on plasmid DNA (pDNA) and 2) facilitate the effective vector unpacking within the cell by a redox mechanism. ${ }^{32}$ The resulting foldamer/pDNA assemblies, referred to as foldaplexes, exhibited high transfection efficiency with gene expression levels comparable to those obtained with branched polyethylenimine (b-PEI), N-[1(2,3-Dioleoyloxy)propyl]- $N, N, N$-trimethylammonium methylsulfate (DOTAP) and LAH4 peptide, a potent 26residue long CPP developed for gene delivery. ${ }^{33}$ CPF 1 which exhibits an amphipathic distribution of side chains along the 2.5-helix axis (Figure 1a), contains only one Argfor two His-type residues per oligourea segment, the Histype residues $\left(\mathrm{His}^{\mathrm{U}}\right)$ being introduced to promote endosomal escape (i.e. so called proton sponge effect). ${ }^{34,35}$ 
In this work, we have considered the possibility to increase further the transfection efficacy by combining the CPF sequence used in $\mathbf{1}$ with a multimeric cationic (Arg-rich) pseudopeptide (N5L) reported to bind nucleoproteins including cell-surface expressed nucleolin (NCL). ${ }^{36,37}$
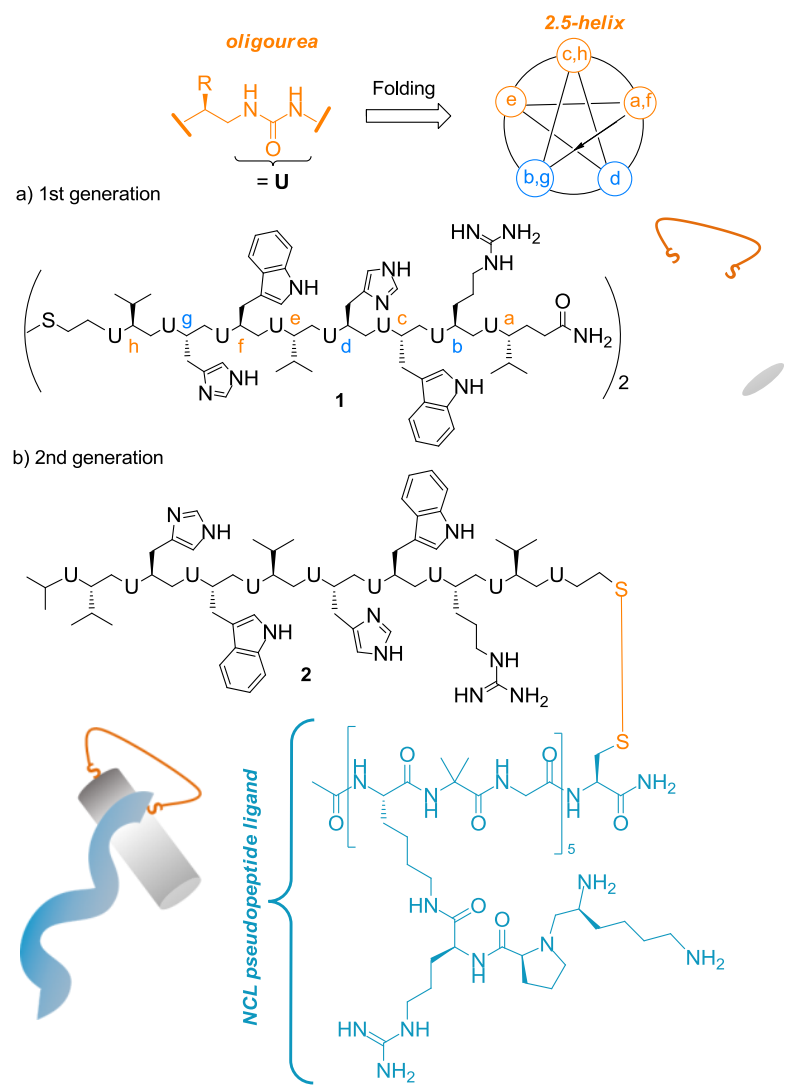

Figure 1. Helical wheel representation of oligourea and formulae of a) the $1^{\text {st }}$ generation of homodimeric urea-based CPF (1) and b) $2^{\text {nd }}$ generation of urea-based foldamer-pseudopeptide hybrid (2).

NCL is known to play a key role in a variety of cellular processes such as transcription, replication and recombination of DNA and its expression although primarily known to be nuclear and cytoplasmic is enhanced at the surface of activated endothelial cells and of various types of cancer cells. ${ }^{38}$ Several recent studies have highlighted the potential of using NCL ligands (e.g. aptamer AS1411, ${ }^{39}$ the homing tumor peptide $\mathrm{F}^{3},{ }^{40}$ and multimeric pseudopeptides) ${ }^{36,41}$ as anticancer agents but also to mediate receptor endocytosis and deliver active molecules into cells. Herein, we report the synthesis of the urea-based foldamer-peptide hybrid dimer (2) in which the CPF sequence of $\mathbf{1}$ was conjugated to a NCL pseudopeptide ligand via a reducible disulfide bond. This new system was evaluated for delivery of pDNA in several cell lines and was directly compared to known CPPs, oligourea $\mathbf{1}$ as well as cognate homodimers (Dim8 and Dim9, vide infra). We found that heterodimer 2 displays a remarkably high transfection efficacy, above that of the comparators in all cell lines tested and particularly in culture medium containing up to $50 \%$ of serum. These results suggest that this dual molecular platform could overcome some of the limitations of other NA delivery systems for in vivo applications.

\section{RESULTS AND DISCUSSION}

Hybrid Cell-Penetrating Foldamer Synthesis. The synthesis of the cysteamine-functionalized CPF sequence $\mathbf{8}$ used for the preparation of heterodimer $\mathbf{2}$ is shown in Scheme 1. The sequence of $\mathbf{8}$ differs from that in $\mathbf{1}$ by the position of the ureido cysteamine moiety. This modification was introduced to facilitate access of the corresponding oligourea using Boc chemistry by avoiding the need for the final HF cleavage of the resin. The solid-phase synthesis (SPS) using Boc chemistry is particularly robust, allowing the preparation of aliphatic oligoureas and related hybrids with good purities and yields. ${ }^{42,43,44,45}$ Here, the elongation of CPFs using Boc-protected activated monomers $\mathbf{A}$ was preferred over the use of azido building blocks ${ }^{44}$ and TFAlabile resins, also because access to the activated His-type monomer required for such $\mathrm{CPF}$ sequences remains limited to its $N$-Boc protected version. ${ }^{45}$ Our new strategy relies on the use of a resin equipped with a cystamine linker that can be cleaved under reductive conditions to release the $\mathrm{CPF}$ with a terminal thiol-function. It is worth mentioning that compared to standard oligourea synthesis on MBHA resin, there is no more requirement to introduce a $\gamma$-amino acid at the first position (see 1), ${ }^{32,46}$ the cystamine-type linker and the first urea bond being stable to TFA treatment. Resins equipped with a cystamine linker have already been described in literature ${ }^{47}$ and we hypothesized that besides its compatibility with the use of TFA needed for the successive, Boc deprotection steps, the disulfide bridge should also be resistant to microwave irradiation applied during the course of SPS. Resin 3 was prepared from MBHA resin as shown in scheme 1 . To readily estimate the loading of resin 3 by colorimetric test (i.e. Kaiser test), the Boc-Lin$\mathrm{OH}$ linker (4) was preassembled in solution ${ }^{48}$ prior to amide bond formation on the resin. Iterative coupling/deprotection cycles of activated succinimidyl carbamate monomers (A) bearing either Trp, Val or His side chains were next performed under classical coupling conditions and microwave irradiation. To note, an Orn-type monomer with an Alloc protecting group was incorporated in $b$ position as a precursor of the Arg-type residue $\left(\operatorname{Arg}^{\mathrm{U}}\right.$ ) because standard guanidine side-chain protecting group could not be used conveniently with our synthesis approach. After chain elongation was completed, resin-bound intermediate 5 was treated with palladiumtetrakis(triphenylphosphine) to remove the Alloc protection on the $\operatorname{Orn}^{\mathrm{U}}$ side chain and guanidinylation was subsequently performed using 1-amidinopyrazole hydrochloride (6) to furnish resin-bound oligourea 7. After final Tos deprotection of the two His ${ }^{\mathrm{U}}$ side chains of 7 , oligourea 8 bearing a cysteamine moiety at first position ${ }^{32}$ was successfully released from the support by reduction of the disulfide bridge in the presence of dithiothreitol (DTT) in basic medium and was recovered in $13 \%$ 
Scheme 1. New methodology relying on the use of a disulfide bridge resin (3) to assemble oligourea 8 on solid support. Abbreviations not defined in text: BOP, (Benzotriazol-1-yloxy)tris(dimethylamino)phosphonium hexafluorophosphate; DIEA, diisopropylethylamine; HOBt, hydroxybenzotriazole; Tos, tosyl; TFA, trifluoroacetic acid.

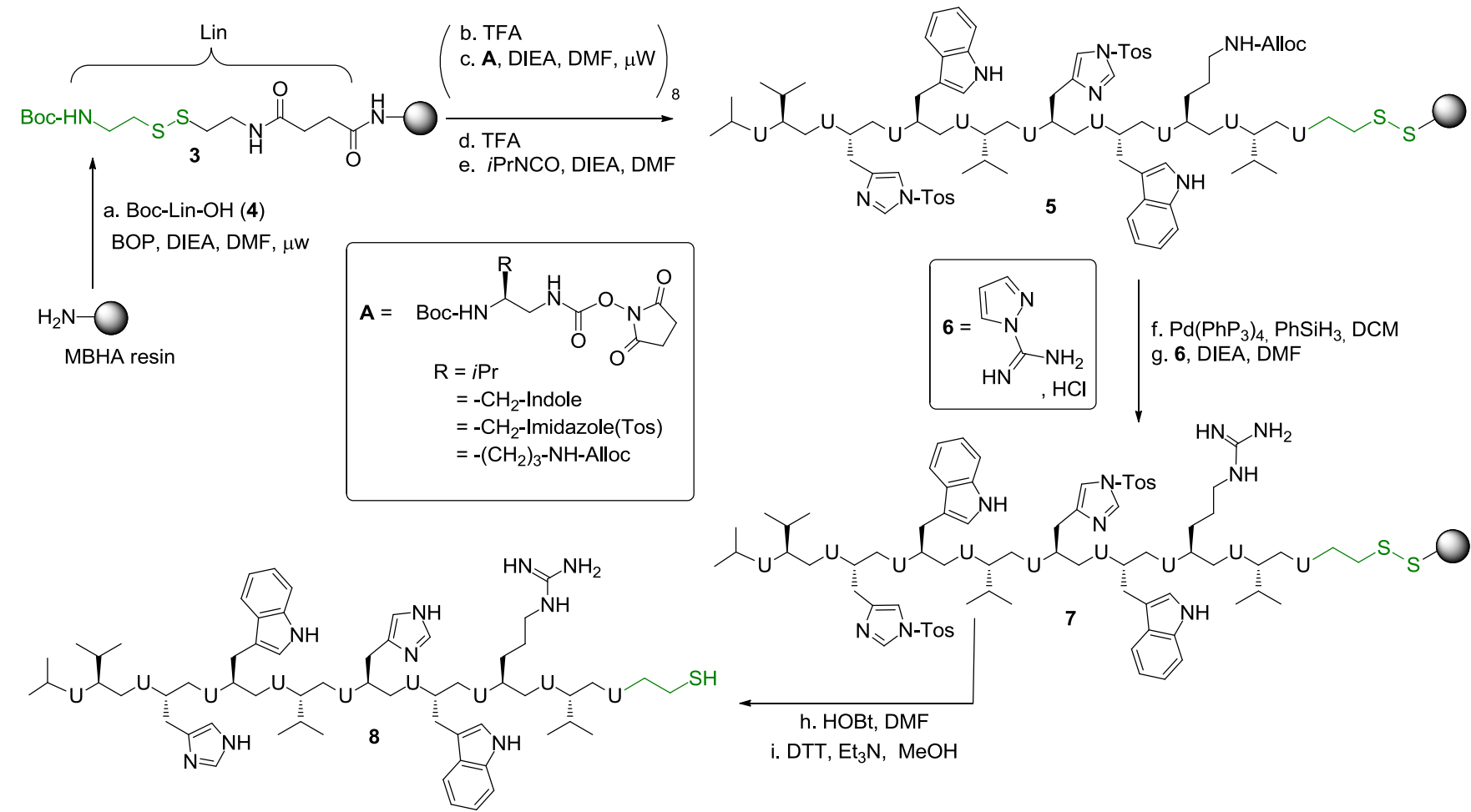

yield after semi-preparative RP-HPLC purification. Heterodimer 2, was then obtained by disulfide bond formation between the C-terminal cysteine modified NCL multivalent ligand $\mathbf{9}^{36}$ and the cysteamine spacer of oligourea $\mathbf{8}$ (Scheme 2). The formation of the disulfide bridge was carried out in two steps by first activating oligourea $\mathbf{8}$ in presence of 2,2'-dithiobis(5-nitropyridine) ${ }^{49}$ and then adding 9 to give 2 in $12 \%$ yield after semi-preparative RPHPLC purification (see experimental section for details). For direct comparison with $\mathbf{1}$ and in order to evaluate the effect on cellular delivery of shifting the cysteamine position, 8 was homo-dimerized to provide Dim8 in $48 \%$ yield. To investigate the ability of the NCL ligand to transfect cells, we also carried out the homodimerization of 9 by DMSO oxidation procedure and the resulting Dim9 was recovered in $72 \%$ yield (see Supporting Information for details).

Circular dichroism (CD) was used to confirm the 2.5helical conformation of the urea-segment composing 2 . The CD spectra, measured either in transfection conditions (150 $\mathrm{mM} \mathrm{NaCl})$ or in phosphate buffer $(40 \mathrm{mM}, \mathrm{pH} 7.4)$, reveal a characteristic signature with a maximum of positive molar ellipticity at about $205 \mathrm{~nm}$ for $\mathbf{2}$ whereas at this wavelength no band is observed for $\mathbf{9}$, thus supporting the presence of a 2.5 -helical secondary structure in $\mathbf{2}$. It is noteworthy that the CD band at $205 \mathrm{~nm}$ is enhanced for $\mathbf{2}$ compared to precursor $\mathbf{8}$ suggesting here strengthening of the helical folding in the hybrid foldamer (see Figure S1 in the Supporting Information).

Plasmid DNA/hybrid CPF assemblies for cell delivery. We next investigated the capacity of 2, Dim8 and Dim9 to associate with a plasmid DNA and transfect cells. Their association with a reporter luciferase expression plasmid (p-Luc) was first explored by performing a gel retardation assay (see Figure S2 in the supporting information). Heterodimer $\mathbf{2}$ was found to interact particularly strongly with NA as revealed by the complete loss of $p$-Luc migration at a $2 / \mathrm{p}$-Luc mass ratio of only 1 . The same experiment with Dim8 showed comparable results to those recently reported for 1 .

The transfection efficiency of the new foldamers was then evaluated using luciferase as reporter gene and human embryonic kidney cells (HEK293) as target cells. CPF 1 and the cationic lipid DOTAP were first used as positive controls. Increasing amounts of $\mathrm{CPFs}$ were mixed with a fixed amount of p-Luc and the transfection capacity of the various compounds was determined by measuring the luminescence of cells (Figure 2a and Figure S3a). This assay showed that hybrid $\mathbf{2}$ exhibited promising transfection capacity with a level of luciferase expression upon transfection of HEK293 cells that compares well with that of DOTAP and exceeds that of $\mathbf{1}$. It is noteworthy that despite the increase of molecular weight, the charge ratio (N/P) of $2(\sim 3)$ remains slightly lower than that of $\mathbf{1}(\sim 3.7)$ with an optimal 2/pDNA mass ratio (2.7) that is about 6 times less important to that of 1 (mass ratio $=16$ ). Having a CPF active at low N/P and w/w ratios is indeed promising because that minimizes the risks of cytotoxicity and immune response potential (vide infra). Moreover, these low ratios ensure that no or only a few of CPF 2 remains uncomplexed in the transfection media. Moreover, these results also reveal that shifting the disulfide bridge from one ex- 
tremity in $\mathbf{1}$ to the other (Dim8) does not alter the transfection capacity of the CPF. In contrast, homodimer Dim9 displayed poor transfection properties demonstrating here the key role played by the oligourea 2.5 -helix component in the DNA association and transfection processes.

With the aim to assess the transfection potential of $\mathbf{2}$, we conducted additional experiments in two other human cell lines: SV40-transformed MRC5 fibroblasts (MRC5-V2) and a breast cancer cell line (MDA-MB-231). Besides DOTAP, the $25 \mathrm{kDa}$ cationic polymer b-PEIErreur ! Signet non défini. which is one of the best vectors to deliver genes and a "golden standard" in transfection assays was also introduced as comparator. The results obtained on these two cell lines unveiled that $\mathbf{2}$ is as good to transfect cells as these two commercially available reagents (Figure $2 b-c$ and Figure S3) at a N/P ratio of solely $1.5-3$ and again superior luciferase expression was observed with foldaplexes composed of $\mathbf{2}$ compared to those formed either in the presence of $\mathbf{1}$ or Dim8 (Figure 2c).

Scheme 2. Synthetic routes to access Dim8 and 2 dimers through disulfide condensation of cysteamine-containing oligourea $\mathbf{8}$.

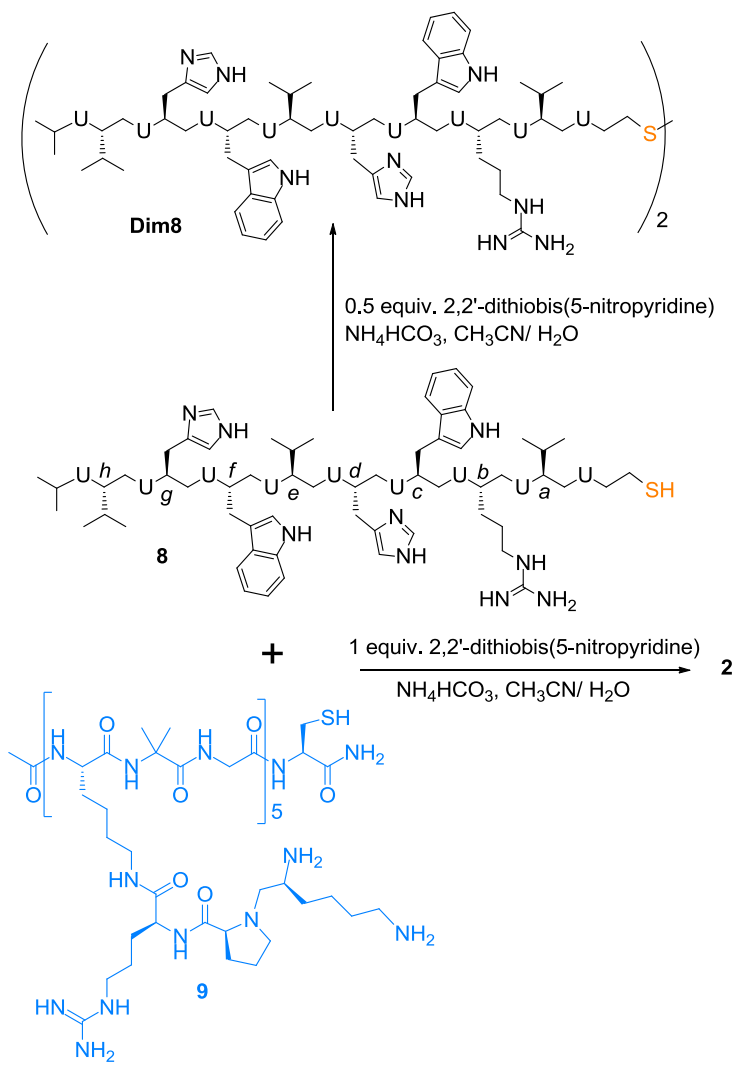

Furthermore, when this transfection experiment was repeated on MDA-MB-231 cells by this time including as controls three CPPs described as being amongst the most potent CPPs for gene delivery, CPF 2 was systematically more effective than LAH4, ${ }^{33}$ LAH4-L1 ${ }^{50}$ and Vpr55-82 $2^{51,52}$ (Figure 2d).
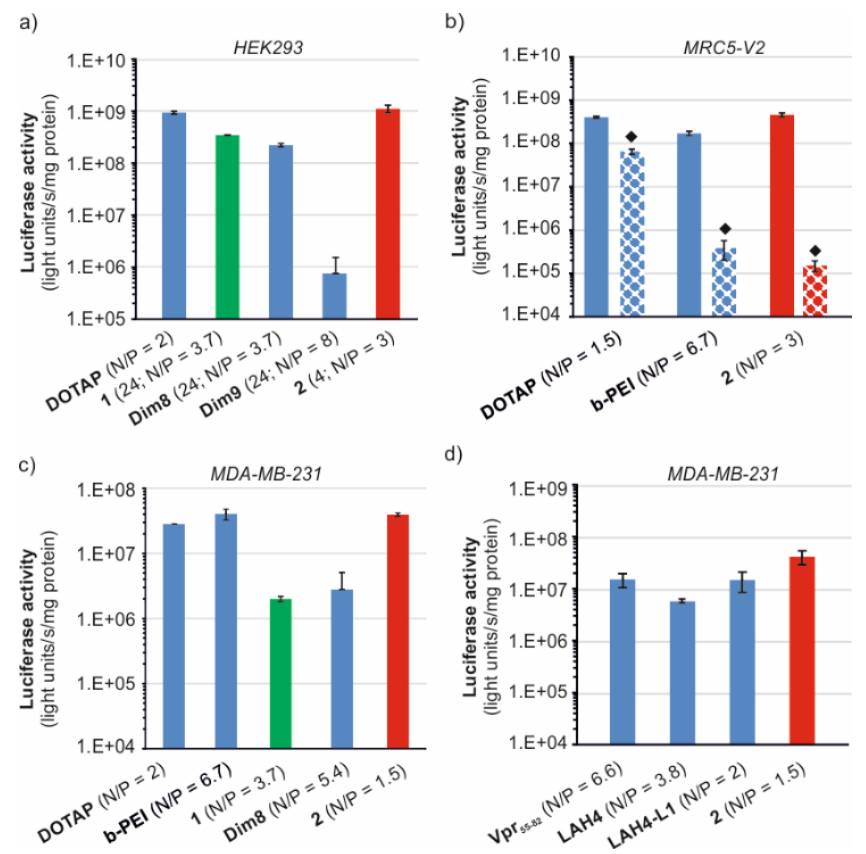

Figure 2. Evaluation of the transfection efficiency of $\mathbf{2}$ and related dimers 1, Dim8 and Dim9. Increasing amounts of transfection reagent were mixed with a constant amount of reporter plasmid (1.5 $\mu \mathrm{g}$ of p-Luc per duplicate). The complexes were incubated for 2-2.5 $\mathrm{h}$ in serum-free medium. Luciferase activity was measured $24-48 \mathrm{~h}$ post-transfection. The transfection efficiency is expressed as total light units per s per mg protein, and the average of duplicates is shown. Here, only are reported the conditions giving the highest luciferase expression. The complete assays are reported in the electronic supplementary information (see Figure S3, S5). a) Transfection of HEK293 cells with p-Luc in the presence of DOTAP (N/P = 2) and the four dimers 1, 2, Dim8 and Dim9. The mass $(\mu \mathrm{g})$ of compounds 1, 2, Dim8 and Dim9 used in the assay and the oligomer/pDNA charge ratio (N/P) are given in brackets; b) MRC5-V2 cells were transfected with DOTAP, PEI or $\mathbf{2}$ in the presence $(\bullet)$ or absence of concanamycin A (15 nM); c) Transfection levels obtained in MDA-MB-231 cells with DOTAP, b-PEI, 1, 2 and Dim8; d) Comparison of the transfection capacity of 2 vs. 3 CPPs namely Vpr55-82, LAH4-L1 and LAH4.

To gain insight into the cell uptake pathway of this second generation of foldaplexes, we next evaluated p-Luc expression after inhibition of the endosome acidification by concanamycin $\mathrm{A}^{53}$ In the presence of this drug, the transfection efficiency of b-PEI and $\mathbf{2}$ was diminished by more than 100- and 1000-fold, respectively (Figure $2 b$ ), whilst that of DOTAP was almost unaltered ( $\sim 3$-fold less luciferase expression). At $\mathrm{pH} 7$, the lipoplexes are indeed already protonated. Similar to what was previously established for homodimer $\mathbf{1},{ }^{32}$ these results emphasize that acidification of endocytic vesicles and therefore the protonation of $\mathrm{His}^{\mathrm{U}}$ residues are required to trigger the release of foldaplexes in the cytoplasm and consequently for an optimal activity of 2.

Additional information regarding the size and surface charge of the 2/pDNA foldaplex assemblies were gathered by performing dynamic light scattering experiments. In the absence of salt, we observed a majority of particles with a 
size of about $100 \mathrm{~nm}$ that compares well to the result previously reported for foldaplexes formed with $1 .^{32}$ In salt-rich conditions $(150 \mathrm{mM} \mathrm{NaCl})$, the foldaplexes were much larger with a mean diameter 10 times bigger $(\approx 1000 \mathrm{~nm})$. Thus, as earlier reported for $\mathbf{1}$ the presence of salts strongly influences the aggregation process. ${ }^{32}$ Finally, the surface charge of the 2/pDNA foldaplexes (generated at the optimal mass ratio (2.7) for in vitro transfection) was investigated by zeta potential measurement and found to be positive (above $+27 \mathrm{mV}$ ) thus rendering the particles capable to enter cells.
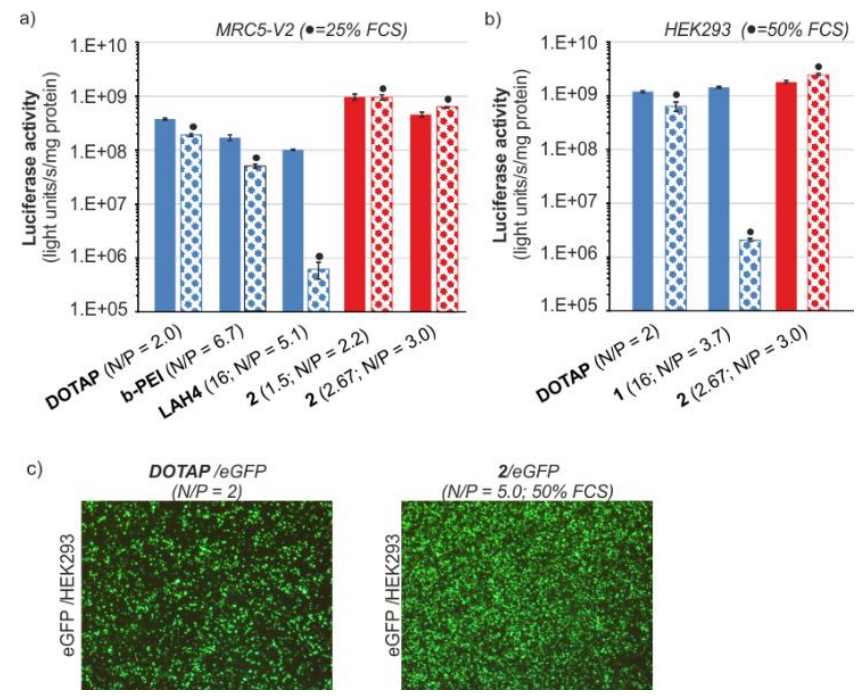

Figure 3. Comparison of the transfection efficiency of $\mathbf{2}$ in serumfree or enriched media. The same conditions to those detailed in Figure 2 were applied. a) Transfection of MRC5-V2 cells with $(\bullet)$ or without the presence of $25 \%$ FCS. In this assay LAH4 peptide was included as control. The mass ( $\mu \mathrm{g})$ of compound used in the assay and the charge ratio (N/P) are given in brackets; b) Transfection of HEK293 cells with culture medium containing $50 \%$ of FCS (•); c) eGFP expression $48 \mathrm{~h}$ after transfection of HEK293 cells with eGFP complexes without serum (photo on the left; with DOTAP as transfection agent) or in the presence of $50 \%$ FCS (right; with CPF 2) $(\mathrm{n}=2)$.

NA transfection in serum-rich media. To further explore the potential of $\mathbf{2}$ as a gene carrier, we next determined the stability and activity of $2 / \mathrm{pDNA}$ foldaplexes in serum-rich media which is more realistic in terms of future in vivo use of this CPF-based delivery system. The recent finding that amphiphilic cationic oligourea sequences related to $\mathbf{8}$ display remarkable resistance to proteolysis and prolonged stability in biological fluids ${ }^{42}$ boded well for an improved behaviour of foldaplexes under such conditions. Up to $50 \%$ of foetal calf serum (FCS) was included in culture media of the three above mentioned cell lines and the level of luciferase expression was again monitored. DOTAP, b-PEI, LAH4 peptide and CPF 1 were included as references in this study (Figure 3a-b and Figure S4 for the MDA-MB231 cell line). Remarkably, the $2 /$ p-Luc foldaplexes were found to be extremely stable in serum-containing media and no loss of transfection capacity was observed in cell culture composed of up to $50 \%$ of FCS. When $25 \%$ FCS was included in the MRC5-V2 cell medium, 2 compared favourably with DOTAP, b-PEI and LAH4. It is likely that the dramatically reduced transfection properties observed for LAH4 reflects its reduced serum-stability (Figure 3a). The same trend was observed on HEK293 cell line with a culture medium composed with 50\% FCS. Whilst 2 exhibits a transfection efficiency unaltered in the absence or presence of serum (Figure 2a), at the opposite $\mathbf{1}$ showed a transfection capacity that was diminished by $\sim 700$ fold. Another feature of 2, worthy to emphasize is that in contrast to DOTAP and b-PEI where an increase of the vector/pDNA mass ratio is needed to compensate serum destabilizing effects on lipo- and polyplexes, ${ }^{54}$ in the case of 2 the same level of luciferase expression is observed in serum-free or enriched conditions illustrating here the remarkable capacity of this molecular transporter to deliver genes (Figure S5).

In addition to these experiments, we analysed HEK293 cells by fluorescence microscopy following transfection with a green fluorescent protein expression plasmid (eGFP) in culture medium containing $50 \%$ FCS. The observed eGFP expression was compared to that produced when DOTAP was employed as transfection agent in a serumfree medium. As shown in Figure 3c, the number of GFP expressing cells $24 \mathrm{~h}$ after transfection with $\mathbf{2}$ is significant and surpasses the level of eGFP expression obtained with DOTAP. a)

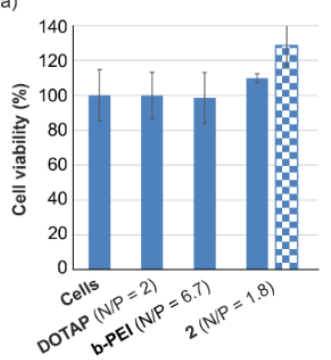

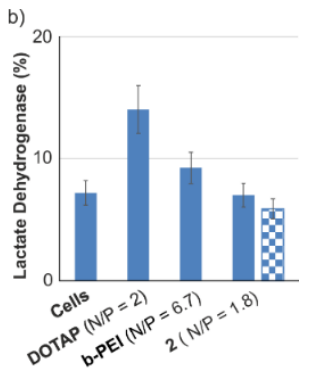

c)

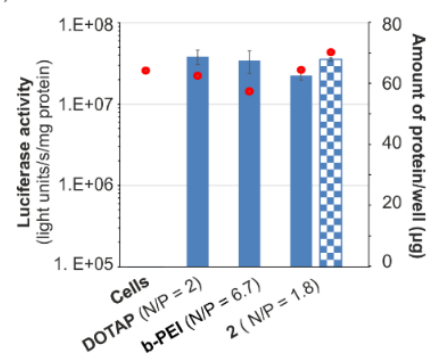

Figure 4. The different transfection reagents were mixed with a constant amount of reporter plasmid $(2.25 \mu \mathrm{g}$ per triplicate $(\mathrm{a}, \mathrm{b})$ and $1.5 \mu \mathrm{g}$ per duplicate (c)) and the complexes were incubated for $2 \mathrm{~h} 40$ with MDA-MB-231 cells in the absence or in the presence (grid bar) of $50 \%$ serum. In graph c) the red dots represent the amount of protein in $\mu \mathrm{g}$ per well (y axis on the right of the graph).

Cytotoxicity determination of hybrid CPF 2. The cytotoxicity of 2/p-Luc foldaplexes was assayed on MDA-MB231 cells by resorting to three different methods. First, cell 
viability was evaluated by performing a 3-(4,5dimethylthiazol-2-yl)-2,5-diphenyltetrazolium bromide (MTT) assay. ${ }^{32}$ The results show that $\mathbf{2}$ did not alter cell proliferation in culture medium containing or not $50 \%$ FCS (Figure 4a). Concurrently, the membrane integrity was assayed by measuring the extracellular activities of lactate dehydrogenase (LDH). The presence of this enzyme in the extracellular environment allows the detection of membrane alteration. We find that b-PEI and DOTAP slightly perturbed the cell membrane with around 1.5 and 2-fold more extracellular LDH respectively than in the control experiment, whilst in the presence of $\mathbf{2}$ no cell membrane alteration is observed whatever the medium (i.e. +/- serum in the culture medium) (Figure 4b). The last assay consisted in the determination of the total protein content after p-Luc transfection. ${ }^{33}$ The data are in agreement with the MTT assay and support the conclusion that CPF 2 seems to be harmless to the cells (Figure 4c).

\section{CONCLUSION}

In summary, we have developed an SPS approach featuring a cystamine-type resin and Boc chemistry to facilitate access to new oligourea sequences equipped with a cysteamine termination for further functionalization using thiol reactivity. This synthesis approach was applied to the preparation of a new generation of CPFs combining a cationic oligourea sequence and a NCL peptide ligand. One such heterodimer (2) was found to be highly potent to deliver pDNA to various human cells and to mediate effective gene expression. It compared favorably with the "golden standard" transfection reagents DOTAP and b-PEI as well as a number of known CPPs. Remarkably, the efficacy of foldaplexes composed of 2 was not affected by the presence of up to $50 \%$ serum in the culture medium and cell cytotoxicity was low. For these reasons, the foldamer-peptide conjugates reported here may represent an alternative to overcome some of the current limitations of CPPs designed to deliver DNA. Future studies will aim at investigating the cell internalization process and at determining if it occurs through a cell-surface nucleolin internalization pathway and whether it is associated with some cell selectivity.

\section{ASSOCIATED CONTENT}

\section{Supporting Information}

The Supporting Information is available free of charge on the ACS Publications website at DOI: $x x x x x x x x x x$

Detailed experimental protocols, materials and methods for cell transfection assays and additional figures S1-S5; synthesis and characterization of linker $\mathbf{4}$ and newly synthesized building block (A) equipped with Orn(Alloc) type side-chain, solid phase synthesis procedure of 8; syntheses of 2, Dim8 and Dim9; HPLC profiles and HRMS analyses of all foldamer hybrids related to this article; CD spectra of $\mathbf{2 , 8}$ and $\mathbf{9}$.

\section{AUTHOR INFORMATION}

\section{Corresponding Author}

* E-mail: g.guichard@iecb.u-bordeaux.fr

* E-mail: kichler@unistra.fr

\section{Notes}

The authors declare no competing financial interest.

\section{ACKNOWLEDGMENTS}

This project was partially funded by IdEx Bordeaux / CNRS Projets Exploratoires Premier Soutien. Predoctoral fellowships from DGA and Conseil Régional de Nouvelle Aquitaine (to S.A.), and from the French Ministry of Research (to M. B.) are gratefully acknowledged. This work has benefited from the facilities and expertise of the Biophysical and Structural Chemistry platform at IECB, CNRS UMS3033, INSERM US001, Bordeaux University, France

\section{REFERENCES}

(1) Hoyer, J., and Neundorf, I. (2012) Peptide Vectors for the Nonviral Delivery of Nucleic Acids. Acc. Chem. Res. 45, 1048-1056.

(2) Bechara, C., and Sagan, S. (2013) Cell-Penetrating Peptides: 20 Years Later, Where Do We Stand? FEBS Lett. 587, 1693-1702.

(3) Boisguérin, P., Deshayes, S., Gait, M. J., O’Donovan, L., Godfrey, C., Betts, C. A., Wood, M. J. A., and Lebleu, B. (2015) Delivery of Therapeutic Oligonucleotides with Cell Penetrating Peptides. Adv. Drug Deliv. Rev., 87, 52-67.

(4) Rothbard, J. B., Kreider, E., VanDeusen, C. L., Wright, L., Wylie, B. L., and Wender, P. A. (2002) Arginine-Rich Molecular Transporters for Drug Delivery: Role of Backbone Spacing in Cellular Uptake. J. Med. Chem., 45, 3612-3618.

(5) Futaki, S., and Nakase, I. (2017) Cell-Surface Interactions on Arginine-Rich Cell-Penetrating Peptides Allow for Multiplex Modes of Internalization. Acc. Chem. Res., 50, 2449-2456.

(6) Takeuchi, T., and Futaki, S. (2016) Current Understanding of Direct Translocation of Arginine-Rich Cell-Penetrating Peptides and Its Internalization Mechanisms. Chem. Pharm. Bull. (Tokyo), 64, 1431-1437.

(7) Tung, C.-H., and Weissleder, R. (2003) Arginine Containing Peptides as Delivery Vectors. Adv. Drug Deliv. Rev., 55, 281-294.

(8) Emi, N., Kidoaki, S., Yoshikawa, K., and Saito, H. (1997) Gene Transfer Mediated by Polyarginine Requires a Formation of Big Carrier-Complex of DNA Aggregate. Biochem. Biophys. Res. Commun., 231, 421-424.

(9) Alhakamy, N. A., Elandaloussi, I., Ghazvini, S., Berkland, C. J., and Dhar, P. (2015) Effect of Lipid Headgroup Charge and pH on the Stability and Membrane Insertion Potential of Calcium Condensed Gene Complexes. Langmuir, 31, 4232-4245.

(10) Wender, P. A., Rothbard, J. B., Jessop, T. C., Kreider, E. L., and Wylie, B. L. (2002) Oligocarbamate Molecular Transporters: Design, Synthesis, and Biological Evaluation of a New Class of Transporters for Drug Delivery. J. Am. Chem. Soc., 124, 13382-13383.

(11) Patil, K. M., Naik, R. J., Rajpal, Fernandes, M., Ganguli, M., and Kumar, V. A. (2012) Highly Efficient (R-X-R)-Type Carbamates as Molecular Transporters for Cellular Delivery. J. Am. Chem. Soc., 134, 7196-7199.

(12) Gellman, S. H. (1998) Foldamers: A Manifesto. Acc. Chem. Res., 31, 173-180.

(13) Guichard, G., and Huc, I. (2011) Synthetic Foldamers. Chem. Commun., 47, 5933-5941.

(14) Wender, P. A., Mitchell, D. J., Pattabiraman, K., Pelkey, E. T., Steinman, L., and Rothbard, J. B. (2000) The Design, Synthesis, and Evaluation of Molecules That Enable or Enhance Cellular Uptake: Peptoid Molecular Transporters. Proc. Natl. Acad. Sci. U. S. A., 97, 13003-13008.

(15) Unciti-Broceta, A., Diezmann, F., Ou-Yang, C. Y., Fara, M. A., and Bradley, M. (2009) Synthesis, Penetrability and Intracellular Targeting of Fluorescein-Tagged Peptoids and Peptide-Peptoid Hybrids. Bioorg. Med. Chem., 17, 959-966.

(16) Murphy, J. E., Uno, T., Hamer, J. D., Cohen, F. E., Dwarki, V., and Zuckermann, R. N. (1998) A Combinatorial Approach to the Discovery of Efficient Cationic Peptoid Reagents for Gene Delivery. Proc. Natl. Acad. Sci. U. S. A., 95, 1517-1522.

(17) Umezawa, N., Gelman, M. A., Haigis, M. C., Raines, R. T., and 
Gellman, S. H. (2002) Translocation of a $\beta$-Peptide Across Cell Membranes. J. Am. Chem. Soc., 124, 368-369.

(18) Potocky, T. B., Menon, A. K., and Gellman, S. H. (2005) Effects of Conformational Stability and Geometry of Guanidinium Display on Cell Entry by Beta-Peptides. J. Am. Chem. Soc., 127, 3686-3687.

(19) Demizu, Y., Oba, M., Okitsu, K., Yamashita, H., Misawa, T., Tanaka, M., Kurihara, M., and Gellman, S. H. (2015) A Preorganized $\beta$-Amino Acid Bearing a Guanidinium Side Chain and Its Use in CellPenetrating Peptides. Org. Biomol. Chem., 13, 5617-5620.

(20) Appelbaum, J. S., LaRochelle, J. R., Smith, B. A., Balkin, D. M., Holub, J. M., and Schepartz, A. (2012) Arginine Topology Controls Escape of Minimally Cationic Proteins from Early Endosomes to the Cytoplasm. Chem. Biol., 19, 819-830.

(21) Daniels, D. S., and Schepartz, A. (2007) Intrinsically CellPermeable Miniature Proteins Based on a Minimal Cationic PPII Motif. J. Am. Chem. Soc., 129, 14578-14579.

(22) Farrera-Sinfreu, J., Giralt, E., Castel, S., Albericio, F., and Royo, M. (2005) Cell-Penetrating Cis- $\gamma$-Amino-L-Proline-Derived Peptides. J. Am. Chem. Soc., 127, 9459-9468.

(23) Gillies, E. R., Deiss, F., Staedel, C., Schmitter, J.-M., and Huc, I. (2007) Development and Biological Assessment of Fully WaterSoluble Helical Aromatic Amide Foldamers. Angew. Chem. Int. Ed., 46, 4081-4084

(24) Iriondo-Alberdi, J., Laxmi-Reddy, K., Bouguerne, B., Staedel, C., and Huc, I. (2010) Cellular Internalization of Water-Soluble Helical Aromatic Amide Foldamers. Chembiochem, 11, 1679-1685.

(25) Tang, H., Yin, L., Kim, K. H., and Cheng, J. (2013) Helical Poly(arginine) Mimics with Superior Cell-Penetrating and Molecular Transporting Properties. Chem. Sci., 4, 3839-3844.

(26) Nagel, Y. A., Raschle, P. S., and Wennemers, H. (2017) Effect of Preorganized Charge-Display on the Cell-Penetrating Properties of Cationic Peptides. Angew. Chem. Int. Ed., 56, 122-126.

(27) Fillon, Y. A., Anderson, J. P., and Chmielewski, J. (2005) Cell Penetrating Agents Based on a Polyproline Helix Scaffold. J. Am. Chem. Soc., 127, 11798-11803.

(28) Wada, S.-I., Hashimoto, Y., Kawai, Y., Miyata, K., Tsuda, H., Nakagawa, O., and Urata, H. (2013) Effect of Ala Replacement with Aib in Amphipathic Cell-Penetrating Peptide on Oligonucleotide Delivery into Cells. Bioorg. Med. Chem., 21, 7669-7673.

(29) Yamashita, H., Oba, M., Misawa, T., Tanaka, M., Hattori, T., Naito, M., Kurihara, M., and Demizu, Y. (2016) A Helix-Stabilized Cell-Penetrating Peptide as an Intracellular Delivery Tool. Chembiochem, 17, 137-140.

(30) Kato, T., Yamashita, H., Misawa, T., Nishida, K., Kurihara, M., Tanaka, M., Demizu, Y., and Oba, M. (2016) Plasmid DNA Delivery by Arginine-Rich Cell-Penetrating Peptides Containing Unnatural Amino Acids. Bioorg. Med. Chem., 24, 2681-2687.

(31) Tian, Y., Zeng, X., Li, J., Jiang, Y., Zhao, H., Wang, D., Huang, X., and Li, Z. (2017) Achieving Enhanced Cell Penetration of Short Conformationally Constrained Peptides through Amphiphilicity Tuning. Chem. Sci., 8, 7576-7581.

(32) Douat, C., Aisenbrey, C., Antunes, S., Decossas, M., Lambert, O., Bechinger, B., Kichler, A., and Guichard, G. (2015) A CellPenetrating Foldamer with a Bioreducible Linkage for Intracellular Delivery of DNA. Angew. Chem. Int. Ed., 54, 11133-11137.

(33) Kichler, A., Leborgne, C., März, J., Danos, O., and Bechinger, B. (2003) Histidine-Rich Amphipathic Peptide Antibiotics Promote Efficient Delivery of DNA into Mammalian Cells. Proc. Natl. Acad. Sci. U. S. A., 100, 1564-1568.

(34) Boussif, O., Lezoualc'h, F., Zanta, M. A., Mergny, M. D., Scherman, D., Demeneix, B., and Behr, J. P. (1995) A Versatile Vector for Gene and Oligonucleotide Transfer into Cells in Culture and in Vivo: Polyethylenimine. Proc. Natl. Acad. Sci. U. S. A., 92, 7297-7301

(35) Kichler, A., Leborgne, C., Coeytaux, E., and Danos, O. (2001) Polyethylenimine-Mediated Gene Delivery: A Mechanistic Study. $J$. Gene Med., 3, 135-144.

(36) Destouches, D., Page, N., Hamma-Kourbali, Y., Machi, V.,
Chaloin, O., Frechault, S., Birmpas, C., Katsoris, P., Beyrath, J., Albanese, P., et al. (2011) A Simple Approach to Cancer Therapy Afforded by Multivalent Pseudopeptides That Target Cell-Surface Nucleoproteins. Cancer Res., 71, 3296-3305.

(37) Destouches, D., Khoury, D. E., Hamma-Kourbali, Y., Krust, B., Albanese, P., Katsoris, P., Guichard, G., Briand, J. P., Courty, J., and Hovanessian, A. G. (2008) Suppression of Tumor Growth and Angiogenesis by a Specific Antagonist of the Cell-Surface Expressed Nucleolin. PLOS ONE, 3, e2518.

(38) Koutsioumpa, M., and Papadimitriou, E. (2014) Cell Surface Nucleolin as a Target for Anti-Cancer Therapies. Recent Patents Anticancer Drug Discov., 9, 137-152.

(39) Wu, J., Song, C., Jiang, C., Shen, X., Qiao, Q., and Hu, Y. (2013) Nucleolin Targeting AS1411 Modified Protein Nanoparticle for Antitumor Drugs Delivery. Mol. Pharm., 10, 3555-3563.

(40) Christian, S., Pilch, J., Akerman, M. E., Porkka, K., Laakkonen, P., and Ruoslahti, E. (2003) Nucleolin Expressed at the Cell Surface Is a Marker of Endothelial Cells in Angiogenic Blood Vessels. J. Cell Biol., 163, 871-878.

(41) Nisole, S., Krust, B., Callebaut, C., Guichard, G., Muller, S., Briand, J. P., and Hovanessian, A. G. (1999) The Anti-HIV Pseudopeptide HB-19 Forms a Complex with the Cell-SurfaceExpressed Nucleolin Independent of Heparan Sulfate Proteoglycans. J. Biol. Chem., 274, 27875-27884.

(42) Teyssières, E., Corre, J.-P., Antunes, S., Rougeot, C., Dugave, C., Jouvion, G., Claudon, P., Mikaty, G., Douat, C., Goossens, P. L., et al. (2016) Proteolytically Stable Foldamer Mimics of Host-Defense Peptides with Protective Activities in a Murine Model of Bacterial Infection. J. Med. Chem., 59, 8221-8232.

(43) Antunes, S., Douat, C., and Guichard, G. (2016) Solid-Phase Synthesis of Hybrid Urea Oligomers Containing Conservative Thiourea Mutations. Eur. J. Org. Chem., 12, 2131-2138.

(44) Douat-Casassus, C., Pulka, K., Claudon, P., and Guichard, G. (2012) Microwave-Enhanced Solid-Phase Synthesis of N,N'-Linked Aliphatic Oligoureas and Related Hybrids. Org. Lett., 14, 3130-3133. (45) Nelli, Y.-R., Douat-Casassus, C., Claudon, P., Kauffmann, B., Didierjean, C., and Guichard, G. (2012) An Activated Building Block for the Introduction of the Histidine Side Chain in Aliphatic Oligourea Foldamers. Tetrahedron, 68, 4492-4500.

(46) Claudon, P., Violette, A., Lamour, K., Decossas, M., Fournel, S., Heurtault, B., Godet, J., Mély, Y., Jamart-Grégoire, B., Averlant-Petit, M.-C., et al. (2010) Consequences of Isostructural MainChain Modifications for the Design of Antimicrobial Foldamers: Helical Mimics of Host-Defense Peptides Based on a Heterogeneous Amide/Urea Backbone. Angew. Chem. Int. Ed., 49, 333-336.

(47) Quideau, S., Douat-Casassus, C., Delannoy López, D. M., Di Primo, C., Chassaing, S., Jacquet, R., Saltel, F., and Genot, E. (2011) Binding of Filamentous Actin and Winding into Fibrillar Aggregates by the Polyphenolic C-Glucosidic Ellagitannin Vescalagin. Angew. Chem. Int. Ed., 50, 5099-5104.

(48) Sun, Q., Kang, Z., Xue, L., Shang, Y., Su, Z., Sun, H., Ping, Q., Mo, R., and Zhang, C. (2015) A Collaborative Assembly Strategy for Tumor-Targeted siRNA Delivery. J. Am. Chem. Soc., 137, 60006010.

(49) Douat-Casassus, C., Darbre, T., and Reymond, J.-L. (2004) Selective Catalysis with Peptide Dendrimers. J. Am. Chem. Soc., 126, 7817-7826.

(50) Mason, A. J., Martinez, A., Glaubitz, C., Danos, O., Kichler, A., and Bechinger, B. (2006) The Antibiotic and DNA-Transfecting Peptide LAH4 Selectively Associates With, and Disorders, Anionic Lipids in Mixed Membranes. FASEB J., 20, 320-322.

(51) Kichler, A., Pages, J. C., Leborgne, C., Druillennec, S., Lenoir, C., Coulaud, D., Delain, E., Le Cam, E., Roques, B. P., and Danos, O. (2000) Efficient DNA Transfection Mediated by the C-Terminal Domain of Human Immunodeficiency Virus Type 1 Viral Protein R. J. Virol., 74, 5424-5431.

(52) Coeytaux, E., Coulaud, D., Le Cam, E., Danos, O., and Kichler, A. (2003) The Cationic Amphipathic Alpha-Helix of HIV-1 Viral 
Protein R (Vpr) Binds to Nucleic Acids, Permeabilizes Membranes, and Efficiently Transfects Cells. J. Biol. Chem., 278, 18110-18116.

(53) Dröse, S., and Altendorf, K. (1997) Bafilomycins and Concanamycins as Inhibitors of V-ATPases and P-ATPases. J. Exp. Biol., 200, 1-8.

(54) Yang, J. P., and Huang, L. (1997) Overcoming the Inhibitory Effect of Serum on Lipofection by Increasing the Charge Ratio of Cationic Liposome to DNA. Gene Ther., 4, 950-960. 
TOC

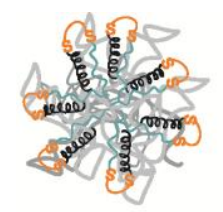

pDNA Foldaplexes

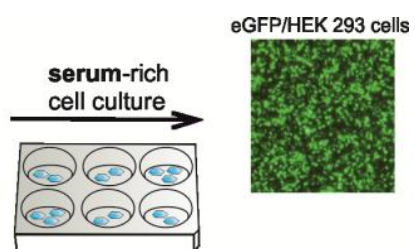

